ORIGINAL ARTICLE

\title{
Skin to calcaneus distance in the neonate
}

\author{
J Arena, J I Emparanza, A Nogués, A Burls
}

Arch Dis Child Fetal Neonatal Ed 2005;90:F328-F331. doi: 10.1136/adc.2004.068064

See end of article for authors' affiliations

.....................

Correspondence to: Dr Emparanza, Clinical Epidemiology Unit, Red $M B E$, Hospital Donostia Apto 477, 20080 San

Sebastian, Basque Country. Spain; jemparan@chdo. osakidetza.net

Accepted

12 February 2005

Published Online First

4 May 2005
Background: Current recommendations for obtaining blood from neonates advise avoidance of the midline area of the heel and are based on postmortem studies.

Objective: Because of the potential pain and tissue damage from repeated heel pricking in the same area, to investigate using ultrasonography whether the distance from skin to calcaneus is less at the midline than at the borders.

Methods: One hundred consecutive healthy preterm and 105 consecutive healthy term neonates were studied 48-72 hours after delivery. The skin to perichondrium distance (SPD) was measured on two occasions by ultrasound at the external, midline, and internal areas of the heel.

Findings: Mean SPD was $0.2 \mathrm{~mm}$ less at the midline than at the other sites. The proportion of measurements $<3 \mathrm{~mm}$ at any of the three sites was the same. Depth was $<3 \mathrm{~mm}$ in less than $3 \%$ of the term and $\sim 20 \%$ of the preterm infants. The SPD correlated only with gestational age. Of children $<33$ weeks gestational age, $38 \%$ had an SPD $<3 \mathrm{~mm}$ compared with $8 \%$ of older preterm infants. The proportions of preterm infants of $\geqslant 33$ weeks gestation and term infants with an SPD $<3 \mathrm{~mm}$ were similar (8\% v $3 \%)$.

Interpretation: With the use of automated lancets of $2.2 \mathrm{~mm}$ length or less, the whole heel plantar surface is safe for obtaining blood in term and preterm infants of $\geqslant 33$ weeks gestation. This means that soft tissue damage and pain from repeated pricking in the same area can be reduced. n recent decades we have become increasingly aware of the fact that neonates experience pain and the importance of minimising this where possible. Blood sampling from the heel is the most common invasive procedure performed on newborn infants. ${ }^{12}$ However, although venepuncture has been shown to be a less painful method for obtaining blood from neonates, ${ }^{3}$ guidelines for newborn screening programmes uniformly recommend heel prick. ${ }^{4}$ Moreover, this is likely to remain the case as the method is more feasible for mass screening, as it is quicker and easier to master and is relatively safe in less skilled hands. ${ }^{5}$

Some early reports described problems with heel lancing, mainly the occurrence of calcaneus osteomyelitis. ${ }^{6-13}$ In 1979 Blumenfeld et al reported that the midline of the heel was not a safe site to puncture with a lancet. ${ }^{14}$ His study was based on postmortem examinations and is the main evidence supporting current recommendations for heel prick guidelines which universally recommend using the internal and external sides and avoiding the midline area of the heel surface.

The restrictions for heel pricking implemented in response to the paper of Blumenfeld et al helped clinicians feel more secure when performing this procedure. However, it also has the consequence that, particularly in sick neonates who may require multiple blood samples, repeated punctures are concentrated in a small area increasing the risk of soft tissue damage, pain, necrosis, and infection.

Over the last decades, cases of reported calcaneus osteomyelitis have diminished. Although this may be attributable to the modification of heel pricking procedures since the research of Blumenfeld et al, ${ }^{14}$ it may also simply be due to the introduction of automated lancets. In contrast with traditional lancets, automated lancets do not require pressure to be exerted on the skin and thereby avoid reducing the skin to perichondrium distance.

In the light of the introduction of automated lancets and the potential pain and problems for neonates who require repeated samples from a restricted area from which to take obtain samples, we felt it important to re-evaluate the findings of Blumenfeld et al, using modern imaging techniques in an in vivo study.

Ultrasonic heel pad measurement has been shown to be an adequate technique in adults. ${ }^{15}$ Its use in neonates to measure the skin to perichondrium distance (SPD) has also been reported. ${ }^{16}$ We therefore conducted an ultrasonographic study in live healthy newborn term and preterm infants to assess the distance between the skin and perichondrium, and hence the safety of heel prick in different parts of the plantar surface of the heel.

\section{METHODS}

\section{Study design}

The protocol of this descriptive study with repeated measurements was approved by the local research ethics committee.

\section{Setting}

A tertiary hospital, serving a population of nearly 700000 inhabitants.

\section{Patients}

Two samples of newborn infants were recruited: 105 consecutive healthy term infants; 100 healthy preterm infants. All were studied 48-72 hours after birth.

\section{Depth measurements}

SPD was measured in three areas: a midline point and the currently recommended sites external and internal to the expected limits of the calcaneus (fig 1).

Depth was measured with an ultrasonographic device (Aloka ssd 680) with a $7.5 \mathrm{MHz}$ transducer. The electronic calliper was placed on the skin at the most superficial surface of the calcaneus, the perichondrium. For every child, images of the coronal and sagittal planes were obtained to assess the minimum distance between the skin and the perichondrium. Coronal plane measures were obtained at $0^{\circ},-45^{\circ}$, and $45^{\circ}$ because the calcaneus of the newborn, in coronal view, is 

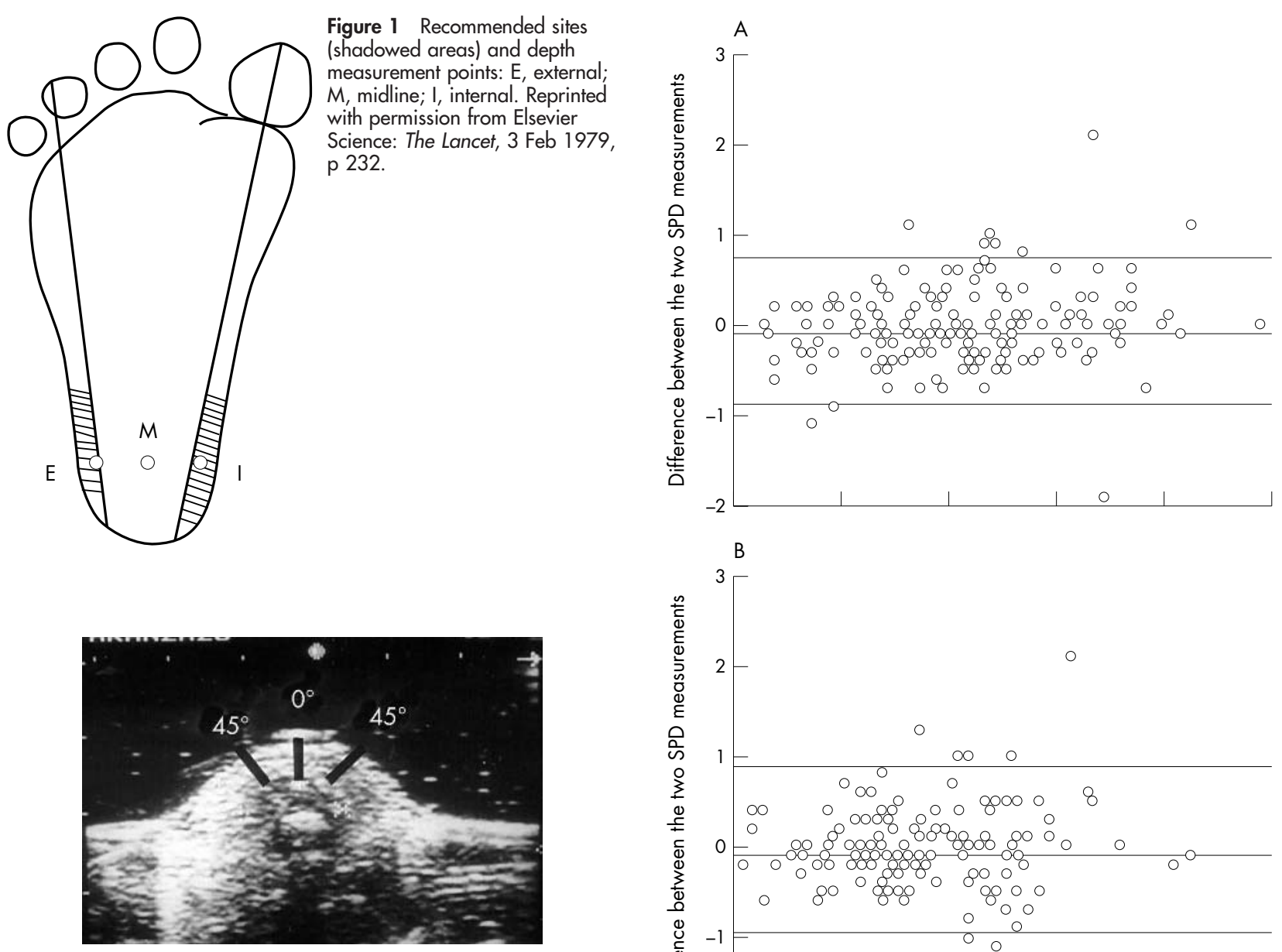

Figure 2 Coronal plane.

spheroid and its external convex surface is an arc running parallel to the cutaneous plantar arc (fig 2).

Measurements were performed by one person (AN). They were repeated within 24 hours, without reference to the previous measure, to assess intraobserver reliability. ${ }^{17}$

The true SPD was taken as the arithmetic mean of the two measures.

\section{Data collection}

Data were recorded on a specially designed sheet, containing the following variables: gestational age, birth weight, sex, current weight, and labour presentation. Data were later transferred to a computer.

\section{Statistical analysis}

Variables were summarised using the mean (SD) for continuous variables, and frequencies and percentages for categorical ones. Intraobserver reliability was assessed using the Bland-Altman graphical method. Repeated measures analysis of variance was used to analyse differences in the three areas considered (internal, external, and midline). The influence of variables on SPD was assessed by linear regression analysis. Proportions were compared using the Fisher exact test. Statistical analysis was performed with SYSTAT 9.0 (SPSS Inc, Chicago, Illinois, USA).

\section{RESULTS}

Table 1 shows the newborn characteristics.

Intraobserver reliability analysis showed excellent agreement between measurements. SPDs were almost identical between the first and second measurement for the three
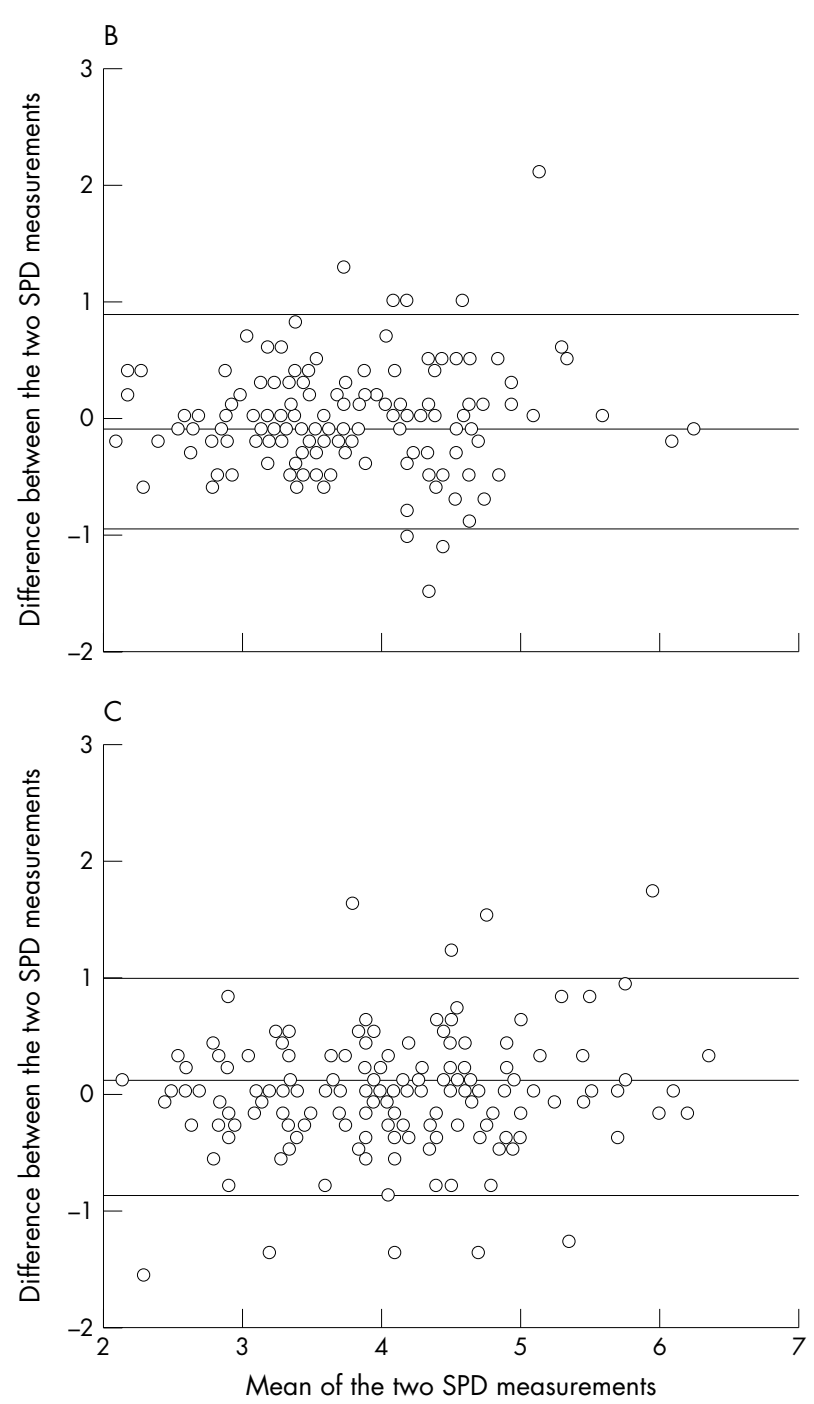

Figure 3 Bland-Altman plots of skin to perichondrium distance (SPD) for the three sites: external (A); midline (B); internal (C).

sites considered (table 2). The same was true for preterm and term newborn measured separately (data not shown). Bland and Altman plots (fig 3) show that the spread of the measurements was acceptable throughout the whole range. 
Table 1 Newborn characteristics

\begin{tabular}{llll}
\hline & Preterm & Term & All combined \\
\hline Sex & & & \\
$\quad$ Female & $47(47 \%)$ & $46(44 \%)$ & $93(45 \%)$ \\
$\quad$ Male & $53(53 \%)$ & $59(56 \%)$ & $112(56 \%)$ \\
Labour presentation & & & \\
$\quad$ Cephalic & $73(73 \%)$ & $95(90 \%)$ & $168(82 \%)$ \\
$\quad \begin{array}{l}\text { Podalic } \\
\text { Other }\end{array}$ & $18(18 \%)$ & $7(7 \%)$ & $25(12 \%)$ \\
Gestational age (weeks) & $93(2.8)$ & $3(3 \%)$ & $12(6 \%)$ \\
Weight (g) & $1871(572)$ & $3291(1.2)$ & $36.3(3.9)$ \\
\hline & & & \\
\hline Values are mean (SD) or number (\%). & & \\
\end{tabular}

Table 2 Repeated measures of skin to perichondrium distance at three sites, expressed in $\mathrm{mm}$, and the mean difference (second - first)

\begin{tabular}{llll}
\hline & First & Second & Mean difference $(95 \% \mathrm{Cl})$ \\
\hline External & 4.11 & 4.11 & $-0.005(-0.811$ to 0.801$)$ \\
Midline & 3.88 & 3.89 & $-0.015(-0.844$ to 0.841$)$ \\
Internal & 4.04 & 4.07 & $-0.034(-0.934$ to 0.866$)$ \\
\hline
\end{tabular}

Table 3 shows the depth at the three sites. The shallowest is at the midline, which was $0.2 \mathrm{~mm}$ less on average. This was statistically significant but is of negligible clinical relevance.

SPD was found to be associated with gestational age, birth weight, labour presentation, and sex in univariate analysis. These variables were introduced into a multivariate model. A backwards stepwise multivariate linear regression model showed that only gestational age was independently associated with SPD at all three sites (correlation coefficients $0.587,0.544$, and 0.596 for external, midline, and internal respectively). The model estimates that the depth of $3 \mathrm{~mm}$ is attained by 28 weeks gestation.

There was no significant difference in the proportion of newborn infants (preterm and term combined) with an SPD $<3 \mathrm{~mm}$ at each of the sites, being about $10 \%$ (table 4 ). Considering preterm infants separately, $20 \%$ of them had an SPD $<3 \mathrm{~mm}$ at the three sites, compared with only $\sim 3 \%$ of term infants.

In subgroup analysis, classifying preterm infants into those $<33$ weeks gestation and those $\geqslant 33$ weeks gestation (table 5 ), $38 \%$ of the former had an SPD $<3 \mathrm{~mm}$ at one or more of the three sites compared with only $8 \%$ of the latter. This difference is significant. The difference in the proportion of preterm infants $\geqslant 33$ weeks gestation with an SPD $<3 \mathrm{~mm}$ $(8 \%)$ was not significantly different from that of term infants $(3 \%)$.

\section{DISCUSSION}

Ultrasound measurement of SPD was shown to be reliable for a given observer, with little variation between measurements. We did not assess whether the measures differ between observers because the purpose of the study was to investigate
Table 4 Proportion of children with skin to perichondrium distance less than $3 \mathrm{~mm}$

\begin{tabular}{llll}
\hline & Preterm & Term & All combined \\
\hline External & $17(17 \%)$ & $4(4 \%)$ & $21(10 \%)$ \\
Midline & $18(18 \%)$ & $3(3 \%)$ & $21(10 \%)$ \\
Internal & $20(20 \%)$ & $2(2 \%)$ & $22(11 \%)$ \\
\hline
\end{tabular}

Table 5 Skin to perichondrium distance by gestational age group

\begin{tabular}{llll}
\hline & $<33$ weeks & $33-<37$ weeks & $\geqslant 37$ weeks \\
\hline $\begin{array}{l}\text { External } \\
<3 \mathrm{~mm}\end{array}$ & $11(32 \%)$ & $6(9 \%)$ & $4(4 \%)$ \\
$\geqslant 3 \mathrm{~mm}$ & $23(68 \%)$ & $60(91 \%)$ & $101(96 \%)$ \\
$\begin{array}{l}\text { Midline } \\
<3 \mathrm{~mm}\end{array}$ & $13(38 \%)$ & $5(8 \%)$ & $3(3 \%)$ \\
$\geqslant 3 \mathrm{~mm}$ & $21(62 \%)$ & $61(92 \%)$ & $102(97 \%)$ \\
$\begin{array}{l}\text { Internal } \\
<3 \mathrm{~mm}\end{array}$ & $15(44 \%)$ & $5(8 \%)$ & $2(2 \%)$ \\
$\geqslant 3 \mathrm{~mm}$ & $19(60 \%)$ & $61(92 \%)$ & $103(98 \%)$ \\
\hline $\begin{array}{l}\text { The group } \\
<3 \text { mm than the other two groups (Fisher exact test, } \mathrm{p}<0.01) \text {. There is no }\end{array}$ \\
significant difference between the other two groups.
\end{tabular}

the relative SPD at the three sites rather than establish an absolute SPD.

Unlike previous postmortem studies, ${ }^{14}{ }^{18}$ ultrasound imaging shows that the SPD is almost identical in the three areas studied. It is not associated with labour presentation, sex, or birth weight. Moreover we adjusted for possible confounders in the analysis, whereas, in the postmortem study, ${ }^{14}$ findings are potentially confounded by birth weight, age, cause of death, and time between death and measurement.

The findings show that the SPD is large enough to assume that automated lancets - that is, spring loaded lancets - of $2.2 \mathrm{~mm}$ are safe for obtaining blood samples in both term and preterm infants over 33 weeks gestational age, regardless of site of puncture.

However, in more than one in three preterm infants $<33$ weeks gestational age, the SPD is $<3 \mathrm{~mm}$. In these preterm infants, neither the lateral (external or internal) nor the midline areas of the heel are deep enough to recommend heel pricking with a $2.2 \mathrm{~mm}$ lancet as a standard procedure.

Preterm children are over-represented by design in this study, with half of the children being preterm. However, most children are not premature (in our region only 5.8\% are). Thus the study's findings have relevance for the vast majority of newborn infants.

For infants who require multiple blood extractions, such as those in neonatal intensive care units, the fact that we can broaden the "safe" pricking area of the heel is important, as it will reduce the local problems and pain when repeated samples are required. We believe that the universal recommendation of avoiding puncturing in the midline of the heel

Table 3 Depth distribution at the three sites

\begin{tabular}{lllll}
\hline Site & Preterm & Term & All & Range \\
\hline External & $3.61(0.66)$ & $4.58(0.81)$ & $4.11(0.88)$ & $2.3-6.9$ \\
Midline & $3.53(0.62)$ & $4.21(0.69)$ & $3.89(0.74)$ & $2.1-6.3$ \\
Internal & $3.58(0.65)$ & $4.51(0.74)$ & $4.06(0.84)$ & $2.2-6.4$ \\
\hline \multicolumn{7}{l}{ Values are mean (SD) expressed in mm. } \\
\end{tabular}


should be revised in the light of evidence from modern imaging techniques and the use of automated lancets.

Further studies in preterm infants would be useful to establish which automated lancet size, if any, is most appropriate at different gestational ages.

\section{Authors' affiliations}

J Arena, Basque Country Newborn Screening Programme, Neonatal Unit, Hospital Donostia, San Sebastian, Spain

J I Emparanza, Clinical Epidemiology Unit, Red MBE, Hospital Donostia

A Nogués, Department of Radiology, Hospital Donostia

A Burls, Department of Public Health, University of Birmingham,

Birmingham, UK

Competing interests: none declared

\section{REFERENCES}

1 Meites S, Glassco KM. Studies on the quality of specimens obtained by skinpuncture of children. 2. An analysis of blood-collecting practices in a pediatric hospital. Clin Chem 1985;31:1669-72.

2 Barker DP, Rutter N. Exposure to invasive procedures in neonatal intensive care unit admissions. Arch Dis Child 1995;72:F47-8.

3 Shah V, Ohlsson A. Venepuncture versus heel lance for blood sampling in term neonates (Cochrane Review). Cochrane Library, Issue 1. Oxford: Update Software, 2000

4 Blood collection on filter paper for neonatal screening programs: approved standard. Villanova, PA: National Committee for Clinical Laboratory Standards; 1989. NCLLS publication LA4-A.
5 Meites S. Skin-puncture and blood-collecting technique for infants: update and problems. Clin Chem 1988;34:890-4.

6 Borris LC, Helleland H. Growth disturbance of the hind part of the foot following osteomyelitis of the calcaneus in the newborn. A report of two cases. $J$ Bone Joint Surg 1986;68:302-5.

7 Goldberg I, Shaver L, Klier I, et al. Neonatal osteomyelitis of the calcaneus following a heel pad puncture: a case report. Clin Orthop 1981;158:195-7.

8 Canale ST, Manugian AH. Neonatal osteomyelitis of the os calcis: a complication of repeated heel punctures. Clin Orthop 1981;156:178-82.

9 Laver BA, Altenburger KM. Outbreak of staphylococcal infections following heel puncture for blood sampling. Am J Dis Child 1981;135:277-8.

10 Uhren R, Curtis P. Calcaneal osteomyelitis of the newborn: a case report. J Fam Pract 1980;11:809-10.

11 Sell EJ, Hansen RC, Struck-Pierce S. Calcified nodules on the heel: a complication of neonatal intensive care. J Pediatr 1980;96:473-5.

12 Lilien LD, Harris VJ, Ramamurthy RS, et al. Neonatal osteomyelitis of the calcaneus: complication of heel puncture. J Pediatr 1976;83:478-80.

13 Abril JC, Aguilar L, Albinana J. Flatfoot and calcaneal deformity secondary to osteomyelitis after neonatal heel puncture. J Pediatr Orthop 1999;8:122-4.

14 Blumenfeld TA, Turi GK, Blanc WA. Recommended site and depth of newborn heel skin punctures based on anatomical measurements and histopathology. Lancet 1979;1:230-3.

15 Rome K, Campbell RS, Flint AA, et al. Ultrasonic heel pad thickness measurements: a preliminary study. Br J Radiol 1998;71:1149-52.

16 Jain A, Rutter N. Ultrasound study of heel to calcaneum depth in neonates. Arch Dis Child Fetal Neonatal Ed 1999;80:F243-5.

17 Hulley SB, Cummings SR. Planning the measurements: precision and accuracy. In: Hulley SB, Cummings SR, eds. Designing clinical research. An epidemiologic approach. Baltimore: Williams \& Wilkins, 1988:31-41.

18 Reiner CB, Meites S, Hayes JR. Optimal sites and depths for skin puncture of infants and children as assessed from anatomical measurements. Clin Chem 1990;36:547-9. 